\title{
LEVANTAMENTO E CARACTERIZAÇÃO DAS UNIDADES DE PAISAGENS DA ÁREA DO PANTANAL DO ABOBRAL - MS
}

\author{
Ednan Aparecido da Silva Theodoro ${ }^{1}$
}

Arnaldo Yoso Sakamoto

\section{RESUMO}

O trabalho foi realizado na sub-região do Pantanal do Abobral, e tem como objetivo, identificar e caracterizar a paisagem da área do Pantanal do Abobral, a sua organização e dinâmica hídrica atual relacionadas com as unidades das paisagens. A metodologia adotada em campo para o estudo da paisagem dessa sub-região foi um levantamento foto descritivo das duas áreas selecionadas, de abrangência do Rio Abobral e a coleta de amostras da cobertura vegetal predominante de cada área estudada, Foi delimitada uma área que corresponde a um quadrado de 20×20, e a identificação das amostras e tabulação em laboratório. As paisagens mesmo com interferência do homem obedecem a um padrão onde em pontos mais altos encontram-se áreas com vegetação mais densa (capão de mata) e no campo com espécimes arbóreos espalhadas de maneira aleatória.

PALAVRAS-CHAVE: Paisagem. Vegetação. Pantanal do Abobral.

\section{SURVEY AND CHARACTERISTICS OF LANDSCAPES UNITS OF PANTANAL DO ABOBRAL - MS}

\footnotetext{
${ }^{1}$ Graduando do Curso de Licenciatura em Ciências Biológicas, UFMS - Campus de Três Lagoas - MS e Bolsista CNPq. E-mail. theodoreodnan@gmail.com

${ }^{2}$ Orientador Professor Doutor do Mestrado Curso de Geografia, UFMS - Campus de Três Lagoas MS. E-mail. arnaldosakamoto@gmail.com

${ }^{3}$ Co-Orientadora Professora Doutora em Agronomia do Curso de Licenciatura em Ciências Biológicas, UFMS - Campus de Três Lagoas - MS. E-mail. tisilica@yahoo.com.br
} 


\begin{abstract}
The work was carried out in the subregion Abobral the Pantanal, and aims to identify and characterize the landscape Abobral the Pantanal area, your organization and current water dynamics related to the units of the landscape. The methodology used in the field to study the landscape of this sub-region was a descriptive photo survey of the two selected areas, spanning the Rio Abobral and collecting samples of the predominant vegetation cover of each study area, an area was delimited corresponding to a square of $20 \times 20$, and sample identification and tabulation in the laboratory. The landscapes even with human interference follow a pattern in which the highest points are areas with denser vegetation (forest gelding) and field with tree specimens scattered randomly.
\end{abstract}

KEYWORDS: Landscape. Vegetation. Pantanal do Abobral.

\title{
ENCUESTA Y CARACTERÍSTICAS DE PAISAJES DE ÁREA DE PANTANAL DO ABOBRAL - MS
}

\section{RESUMEN}

El trabajo se llevó a cabo en la subregión Abobral el Pantanal, y tiene como objetivo identificar y caracterizar el paisaje Abobral la zona del Pantanal, su organización y la dinámica del agua de actualidad relacionados con las unidades de paisaje. La metodología utilizada en el campo para estudiar el paisaje de esta subregión fue una encuesta foto descriptiva de las dos áreas seleccionadas, que abarca el Río Abobral y la recolección de muestras de la cubierta vegetal predominante de cada área de estudio, un área fue delimitada correspondiente a un cuadrado de 20x20, y la identificación de la muestra y la tabulación en el laboratorio. Los paisajes, incluso con la interferencia humana siguen un patrón en el que los puntos más altos son las zonas con vegetación más densa (castrado bosque) y el campo con ejemplares de árboles dispersos al azar.

PALABRAS CLAVE: Paisaje. Vegetación. Pantanal Abobral.

\section{INTRODUÇÃO}

O Pantanal sul mato-grossense, esta localizado na porção central da América do Sul, é reconhecido como uma das maiores áreas úmidas do mundo, com cerca de 200.000 km² (SCOTT, 1991; POR 1995, citado em FURQUIM, 2007). É também considerado como uma das maiores planícies de sedimentação ocupa boa parte da região oeste do Brasil, mas se estende pela Bolívia, Paraguai e Argentina. Tem seus limites marcados por elevações formados por chapadas e depressões 
rasas e é cortada por uma grande quantidade de rios.

O Pantanal foi dividido em 11 sub-regiões distintas conforme as diferenças de características hidrológicas, solo e vegetação (SILVA; ABDON, 1998). O trabalho foi realizado na sub-região do Pantanal do Abobral. Ravaglia et. all (2010) diz sobre a localização dessa sub-região: "O Pantanal do Abobral está localizado nas

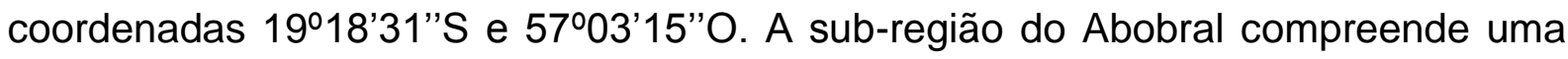
área de $2.833 \mathrm{~km}^{2}$, localizada no Mato Grosso do Sul”. Allen Valls (1986) classifica essa região como: "A sub-região do Abobral é uma das mais baixas, sendo umas das primeiras a inundar, no período das chuvas. A vegetação é do tipo savana e campo, onde são encontradas extensões consideráveis de campos limpos e sujos, intercalados com pequenos capões esparsos". Esse trabalho teve como objetivo identificar e caracterizar os atuais processos existentes na paisagem da área do Pantanal do Abobral, o seu arranjo espacial, a sua organização, relacionadas com as unidades das paisagens.

Sakamoto (1997) ressalta a importância do entendimento da dinâmica ambiental, supondo que a paisagem da área estaria em estreita relação com a água, o relevo, o solo e a vegetação. A pesquisa teve como prioridade a cobertura vegetal predominante dessa sub-região escolhendo duas áreas com aproximadamente $6 \mathrm{~km}$ de distância uma da outra.

Os estudos propostos concordam plenamente com as diretrizes relacionadas ao ensino a pesquisa e a extensão sobre os conhecimentos da natureza para a preservação dos recursos naturais do Pantanal.

\section{OBJETIVOS}

Identificar e caracterizar os atuais processos existentes na paisagem da área do Pantanal do Abobral, a sua organização e dinâmica hídrica da paisagem atual relacionadas com as unidades das paisagens.

\section{MATÉRIAIS E MÉTODOS}

A metodologia adotada em campo foi levantamento foto descritivo das duas áreas de abrangência do Rio Abobral e a coleta de amostras da cobertura vegetal 
para o levantamento das espécies predominante, onde foi delimitada uma área que corresponde a um quadrado de 20x20 (SILVA 2004). As amostras foram tabuladas e identificadas no laboratório.

Para a realização do levantamento de campo, foram utilizados os seguintes materiais.

- Fita zebrada, para delimitação do perímetro de observação da vegetação;

- Trena, para demarcar a área;

- Tesoura de poda, para coleta de amostras (plantas);

- GPS, para fazer o registro das coordenadas geográficas;

- Jornal, para armazenar e organizar as amostras;

- Sacos de coleta, para embalar as amostras;

- Máquina fotográfica, para registrar e documentar as plantas (amostras);

- Caixa de isopor, para realizar o transporte das amostras;

- Prancha de medida universal para coleta de vegetação.

\section{RESULTADOS E DISCUSSÃO}

O Pantanal do Abobral está localizado nas coordenadas 19018'31'S e 5703'15"O (figura: 1). A sub-região do Abobral compreende uma área de 2.833 km², localizada no Mato Grosso do Sul. (RAVAGLIA et al., 2010). 
Figura 1: Localização da sub-região do Pantanal do Abobral.

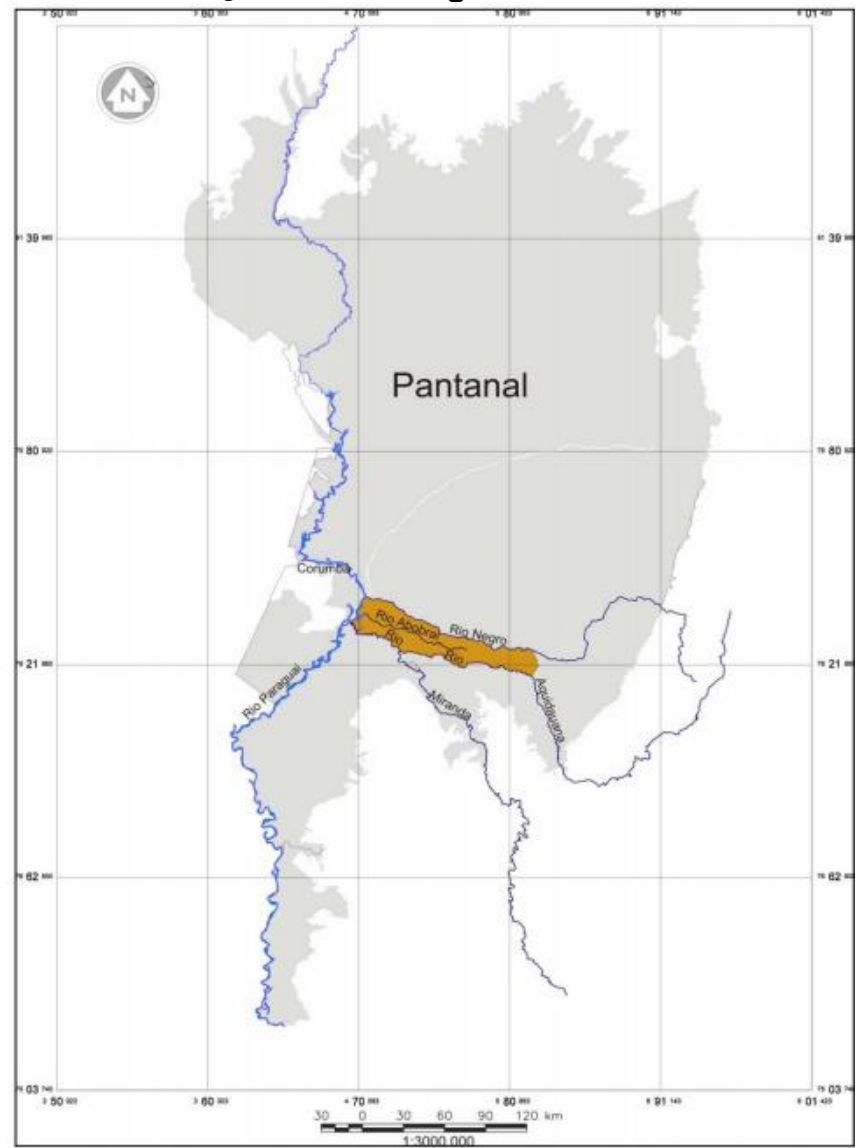

Fonte: RAVAGLIA (2010)

Essa sub-região do Pantanal constitui de uma planície de inundação comum nas épocas das cheias dos Rios Abobral, Negro e Miranda, e é formada por uma topografia de desnível baixo.

Os levantamentos de dados e coletas foram feitas em duas áreas: uma na área de campo e a outra, ao longo da margem do Rio Abobral com aproximadamente $6 \mathrm{~km}$ de distância de um ponto ao outro:

A primeira área está localizada na Fazenda São Bento, sua paisagem corresponde a uma grande área coberta por gramíneas e com algumas árvores esparsas de forma aleatória; em áreas mais elevadas da planície (aproximadamente $3 \mathrm{~m}$ ) há a formação de capão de mata (pequena porção de vegetação) também distribuído de maneira aleatória e algumas áreas se encontravam alagadas, na ocasião da coleta. 
Figura 2: Localização da área de amostragem

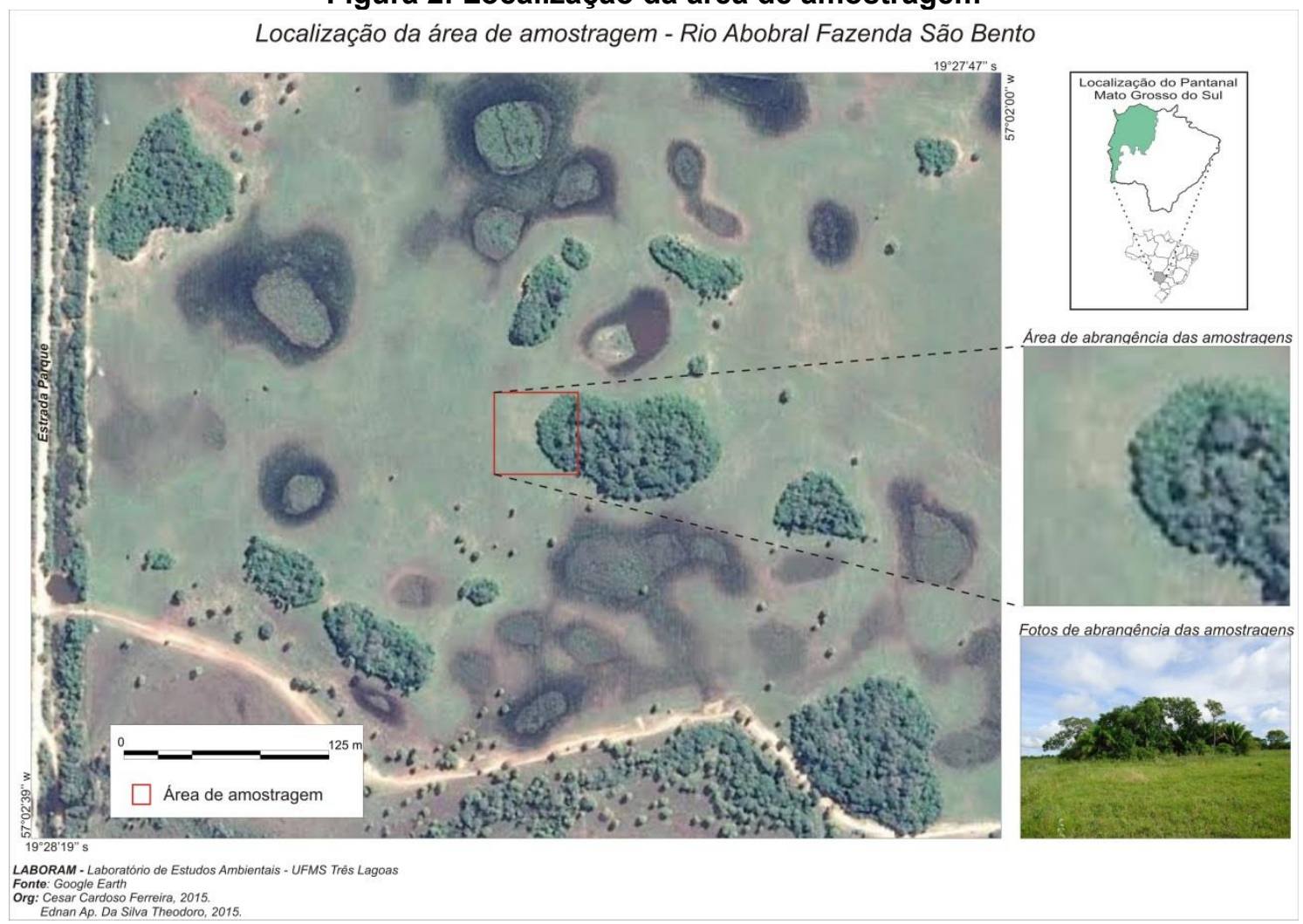

Para a identificação da vegetação na área, foram coletadas amostras de plantas que se apresentavam em maior abundância nos dois pontos escolhidos.

Primeiro ponto corresponde a um capão, onde predominava a espécie Attalea phalerata, ausência de vegetação rasteira no interior do capão e presença de vegetação arbórea, que ao longo da borda ultrapassavam os limites do capão. $O$ solo é arenoso com pequenas elevações com aproximadamente 3 metros, algumas espécies se encontravam queimadas. 
Figura 3: Primeiro ponto de coleta.

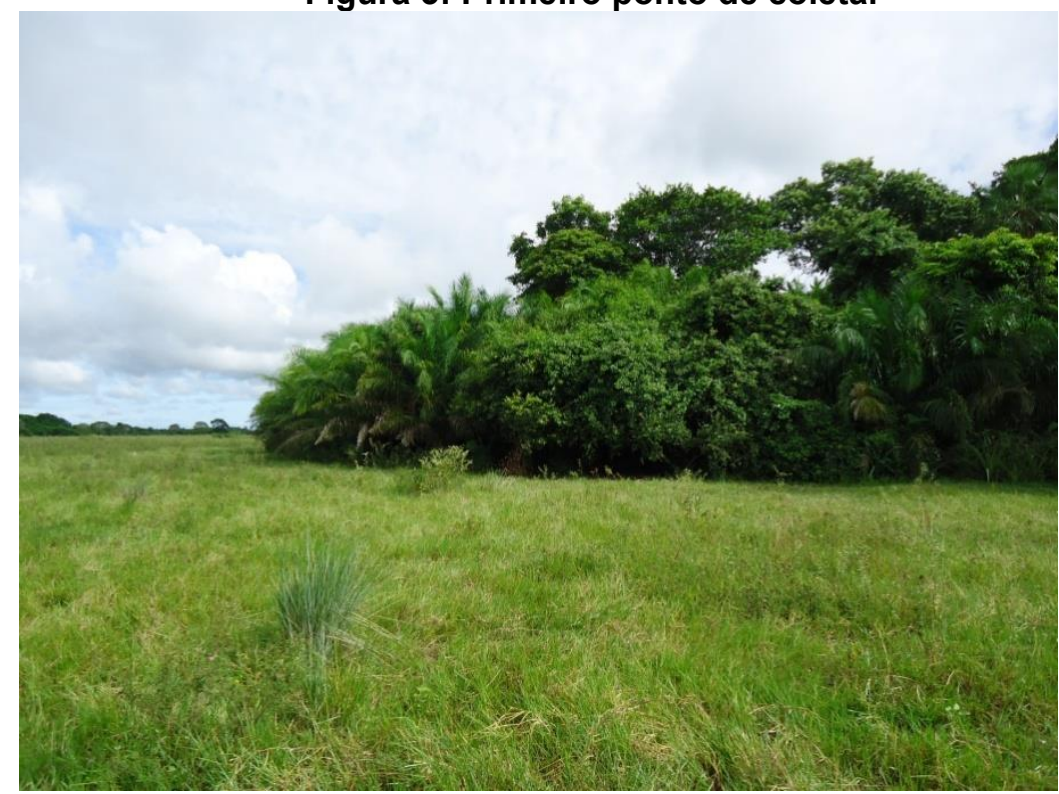

Fonte: ARQUIVO PESSOAL (2014)

\section{Lista de espécies encontradas.}

Família: Arecaceae

Espécie: Attalea phalerata (Mart.) Bur.

Nome popular: acuri.

Palmeira de 2-12 m alt., inflorescências unissexuadas na mesma planta, junout. Fruto verde quase o ano todo e cai no inverno. Usa-se como alimento tanto seu fruto como suas folhas de uso medicinal (POTT 1994).

Família: Bromeliaceae

Espécie: Bromelia balansae Mez

Nome popular: gravateiro

Erva perene, rizomatosa, 0,3-2,0 m alt, conforme o ambiente (mais alta na mata). Flor set-fev, fruto dez-jan. Sua fibra pode ser usada para confecções de artesanatos, seu fruto pode ser comido, como proteção para alguns animais, seu uso medicinal pode ser feito um xarope para tosse com seu fruto e tem fator anestésico (POTT 1994). 
Espécie: Coccolo bamollis Casar

Nome popular: não apresenta

Árvore 4-12 alt. Ás vezes com vários caules (onde há queimada), flor setnov, fruto nov-jan, fruto comido e disseminado por aves, caules e ramos ocos têm pequenas formigas (POTT 1994).

Família: Chrysobalanaceae

Espécie: Licania parvifolia Huber

Nome popular: pimenteira

Árvore 4-10 m alt, tronco geralmente ramificado. Folha muitas vezes com desenhos de insetos minador. Flor mai-jul, ás vezes parcial até nov ou fev, fruto outdez e também escalonado. Serve como abrigo e alimento para animais (POTT 1994).

O segundo ponto corresponde a um campo aberto composto por vegetação rasteira, algumas espécies de pequeno porte, árvores de grande porte que se apresentavam floridas e espalhadas de maneira aleatória pelo campo, e com presença de capão.

Figura 4: Segundo ponto de coleta

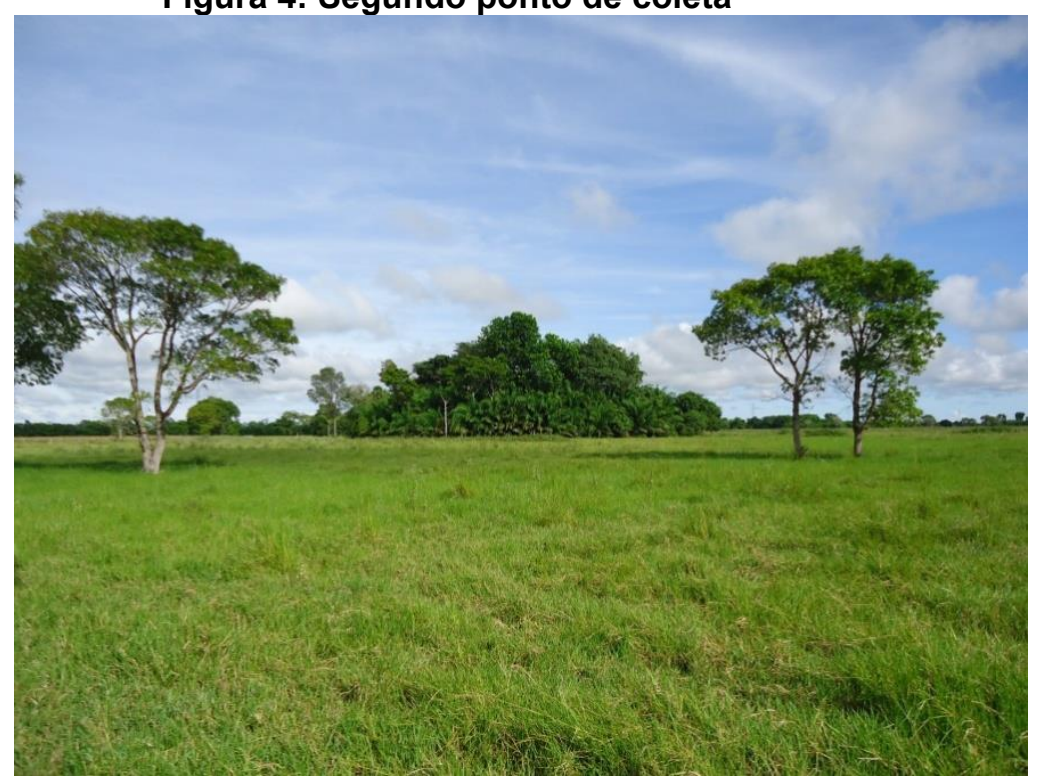

Fonte: ARQUIVO PESSOAL (2014) 


\section{Lista de espécies encontradas.}

Familia: Leguminosae-Caesalpinoideae

Espécie: Hymenaea stigonocarpa (Mart.) Hayne

Nome popular: jatobá

Árvore ereta até $5 \mathrm{~m}$ alt (no campo) a $20 \mathrm{~m}$ alt. (no cerradão), casca rugosa, folha nova avermelhada, flor out-dez, fruto jul-nov, plântula fev-abr. Usado para o fornecimento de farinha, fruto comestível (POTT 1994).

Família: Vochysiaceae

Espécie: Vochysia divergens Pohl

Nome popular: cambará

Árvore ereta, 5-18 m alt, copada, flor ago-set, algumas jan-jun, outras outnov, fruto no início da estação chuvosa. Usada como alimento e abrigo, na medicina pode ser feito um xarope de sua casca com mel para tosse e gripe o chá da folha contra asma, gripe e apendicite e a seiva serve de colírio (POTT 1994).

Família: Euphorbiaceae

Espécie: Sapium haematospermum (M. Arg.). Hub.

Nome Popular: leiteira

Árvore 2-12 m alt, copada, casca grossa, flor set-dez, fruto na estação chuvosa, dez-fev. Usada à madeira para celulose, esculturas, violino, avião e planador. Serve para cerca viva. Látex irritante de pele e mucosa, famoso contra verrugas, remédios para feridas e picada de cobra. Frutos procurados por aves que dispersam as sementes (POTT 1994).

Família: Compositae

Espécie: Stilpnopappus trichospiroides Mart. ex DC

Nome popular: não apresenta.

Erva perene, rasteira ou ascendente no meio de outras plantas, $5-25 \mathrm{~cm}$ alt, flor no ano todo. Pode ser usada como planta ornamental (POTT 1994).

A segunda área encontra-se na Pousada Santa Clara em uma área de 
camping na margem do Rio Abobral, sua paisagem corresponde a uma mata fechada cercada (na encosta do rio) e no campo foi notado que há uma maior concentração de árvores espalhadas de maneira aleatória e nas proximidades há a construção de uma pousada.

Figura 5: Localização da área de amostragem

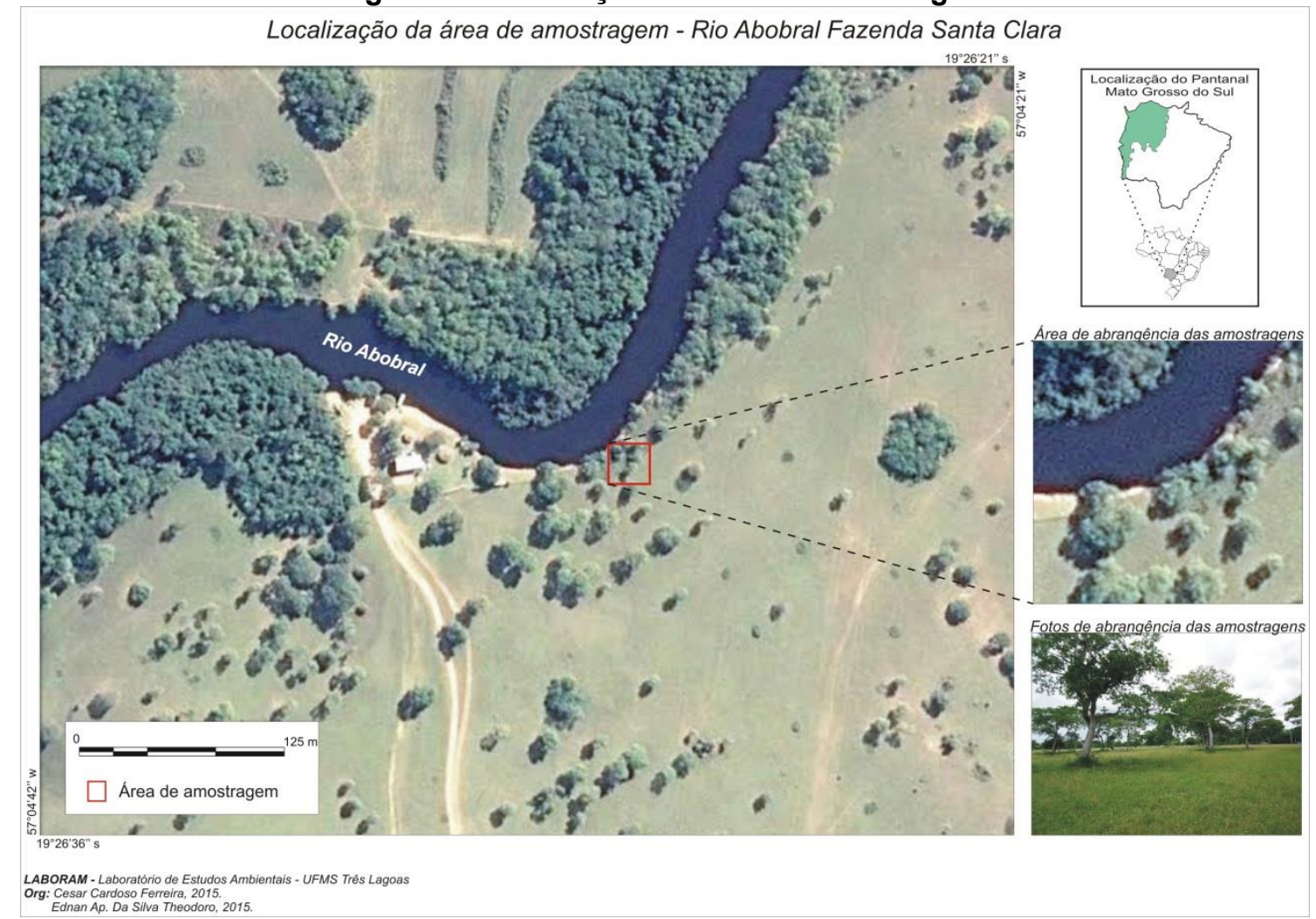

O ponto de coleta da vegetação corresponde a uma mata próxima a margem do Rio Abobral, com espécies arbóreas predominantes e vegetação rasteira e cercada, mata fechada. 
Figura 6: ponto de coleta da vegetação.

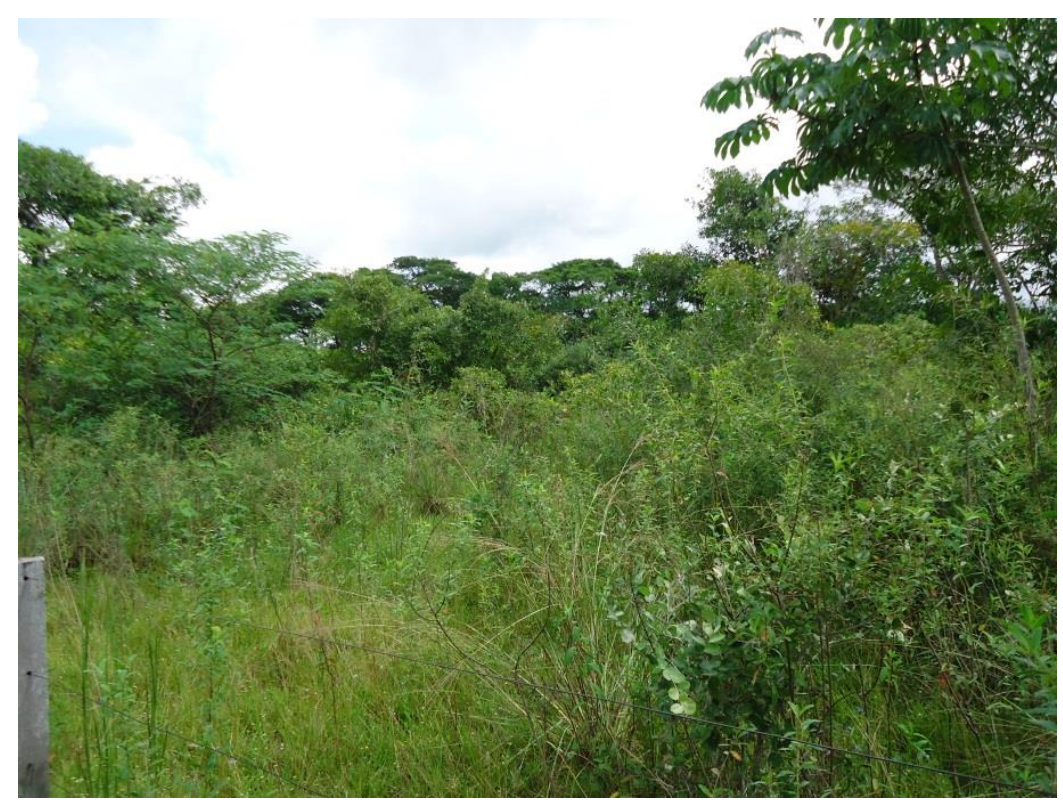

Fonte: ARQUIVO PESSOAL (2015).

\section{Lista de espécies encontradas.}

Família: Connaraceae

Espécie: Connarus suberosus Planch.

Nome popular: araribá-do-campo

Arbusto a árvore, 1,5-5 me alt. Casca com cortiça grossa, flor ago-nov, fruto nov-fev. Potencial ornamental (POTT 1994).

Família: Clusiaceae

Espécie: Calophyllum brasiliense Camb.

Nome popular: guanandi

Árvore de tronco reto ou copa baixa se isolada, 5-20 m altura, látex amarelado, flor ago-out, ás vezes fev-abr (POTT 1994).

Família: Smilacaceae

Espécie: Smilax fluminensis Steud

Nome popular: japecanga

Cipó de 1-6 m de altura, base subterrânea, com muitos caules; flor e fruto no 
verão chuvoso utilizada na alimentação pelo seu alto nível de cálcio (POTT 1994).

Família: Arecaceae

Espécie: Bactris glaucescens Drude

Nome popular: tucum

Palmeira com 1-4 m de altura, em agrupamentos densos, flor mai-dez, fruto dez-mai, pode ser utilizado como isca para pesca (POTT 1994).

\section{CONCLUSÕES}

Mesmo com diferença encontradas em sua composição floral e a presença de construção, a paisagem se mantém composta por um capão e uma grande área forrada por gramíneas e espécies arbóreas formando um campo. Todas as espécies encontradas, possuem um grande valor ecológico, pois são usadas muitas vezes de abrigos e fontes de alimento para muitos animais que vivem nessa região e muitas espécies são usadas de forma medicinal desde colírios a chás para tosse como, por exemplo, a B.balansae; outras espécies podem ser usadas para coberturas de construções no caso da $A$. phalerata devido à morfologia de sua folha.

Foi possível notar que na primeira área houve alteração em sua paisagem para a cultura de gado de corte, já na segunda área foi viável manter a paisagem natural para fins turísticos. 


\section{REFERENCIAL BIBLIOGRÁFICO}

ALLEM, A. C., VALLS, J. F. M. Recursos forrageiros nativos do Pantanal Mato-Grossense. Brasília, DF: EMBRAPA-CENARGEN, 1987. 339 p. (EMBRAPA-CENARGEN. Documentos, 8).

FURQUIM, S.A.C. Formação de carbonatos e argilo-minerais em solos sódico do Pantanal sulmato-grossense. Tese (Doutorado em Geografia Física) - Faculdade de Filosofia, Letras e Ciências Humana da Universidade de São Paulo, São Paulo, 2007.

POTT, A.; POTT, V.J. Plantas do Pantanal / Empresa Brasileira de Pesquisa Agropecuária, Centro de Pesquisa Agropecuária do Pantanal - Corumbá, MS EMBRAPA-SPI, 1994. 320 P.

RAVAGliA, A. G.; SANTOS, S. A.; PELleGRIN, L. A.; RODELA, L. G.; BARBOSA, A. de J. Classificação preliminar das paisagens da sub-região do Abobral, Pantanal, usando imagens de satélite. Corumbá: Embrapa Pantanal, 2010. 4 p. (Embrapa Pantanal. Comunicado Técnico, 82).

SAKAMOTO, A. Y. Dinâmica hídrica em uma lagoa "salina" e seu entorno no Pantanal da Nhecolândia: contribuição ao estudo das relações entre o meio físico e a ocupação, fazenda São Miguel do Firme, MS. 1997. 180 f. Tese (Doutorado em Geografia Física) - Faculdade de Filosofia, Letras e Ciências Humana da Universidade de São Paulo, São Paulo, 1997.

SILVA, J. S. V.; ABDON, M. M. Delimitação do Pantanal e suas Sub-regiões. Pesq. Agropec. Bras., Brasília, v. 33, Número Especial, p. 1703-1711, out. 1998.

SILVA M. H. S. Estudo da Organização da Morfologia dos Solos em Lagoas Salinas no Pantanal da Nhecolândia, MS. Monografia. Departamento de Ciências Humanas. Universidade Federal de Mato Grosso do Sul, Três Lagoas, MS, 2004. 